\title{
Lack of Additional Benefit with High Doses of Corticoste- roids Among Patients with Chikungunya Viral Infection in the Subacute Phase
}

Jamilly Alves Padilha, ${ }^{1}$ Victória Winkler Vasconcelos, ${ }^{1}$ Mariana do Socorro Maciel Quaresma, ${ }^{2}$ Rita Catarina Medeiros Souza, ${ }^{3}$ Cezar Augusto Muniz Caldas*4

${ }^{1}$ Research Fellow, Faculdade de Medicina, Universidade Federal do Pará, Brazil

${ }^{2}$ Assistant Professor, Faculdade de Medicina, Universidade Federal do Pará, Brazil

${ }^{3}$ Assistant Professor, Tropical Medicine Center, Universidade Federal do Pará, Brazil

${ }^{4}$ Assistant Professor, Faculdade de Medicina, Universidade Federal do Pará, Brazil

\begin{abstract}
Background: Scientific evidence regarding the best dose of corticosteroids for the treatment for Chikungunya virus (CHIKV) infection in the subacute phase to relieve symptoms is lacking.

Objectives: This study aimed to evaluate the effect of corticosteroid therapy on the treatment of subacute Chikungunya.

Methods: This prospective cohort study involved patients with subacute CHIKV treated at the Tropical Medicine Center of Pará Federal University, Brazil. The data were collected between January 2019 and January 2020 during the following two periods: the initial consultation of patients and the return visit. A physical examination, in which the occurrence of inflammatory signs was checked and the number of painful and swollen joints was evaluated, was performed by a rheumatologist.
\end{abstract}

Results: Data from 65 subjects were analysed with a predominance of females (80\%), a mean age of $53.5 \pm 13.5$ years and a disease duration of $50.0 \pm 20.8$ days. In this study, $75.4 \%$ of the patients used corticosteroids, $73.8 \%$ of whom progressed to chronic disease and $26.2 \%$ of whom were cured. Although the re-evaluation consultation showed evident improvement in the initial symptoms, the use of a cumulative dose of corticosteroids above $350 \mathrm{mg}$ of prednisone did not affect the outcomes compared to doses less than or equal to $350 \mathrm{mg}$ of prednisone.

Conclusion: In conclusion, for patients infected with CHIKV in the subacute phase, doses of prednisone above $350 \mathrm{mg}$ do not affect the outcome, and the preference for the use of corticosteroids at the lowest dose for the shortest possible time should be reinforced.

Keywords: Chikungunya virus, Arthralgia, Arthritis, Corticosteroids, Treatment

\section{Introduction}

Chikungunya virus (CHIKV) is a flavivirus belonging to the family Togaviridae and genus Alphavirus. The geographical distribution of CHIKV has been demonstrated most intensely in countries in Africa and Asia, and the migratory flow of travellers facilitates

the spread of the virus. ${ }^{1}$ In Brazil, the first documented case of in digenous transmission occurred in the second half of 2014 in the municipality of Oiapoque, Amapá ${ }^{2}$ The disease caused by CHIKV is subdivided into acute, subacute and chronic phases, depending
Quick Response Code:

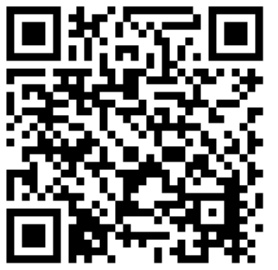

*Corresponding author: Cezar Augusto Muniz Caldas, Internal Medicine Department, Faculdade de Medicina da Universidade Federal do Pará, Avenida Generalíssimo Deodoro, 01-Bairro: Umarizal. CEP 66050-160. Belém-PA, Brazil

Received: 28 January, 2021

Published: 09 February, 2021

Citation: Jamilly AP, Victória WV, Mariana SMQ, Rita CMS, Cezar AMC. Lack of Additional Benefit with High Doses of Corticosteroids Among Patients with Chikungunya Viral Infection in the Subacute Phase. SOJ Complement Emerg Med. 2021;1(1):1-5. DOI: 10.53902/SOJCEM.2021.01.000502 
on the time of instillation. During the subacute phase, which is the subject of this article, from 14 days to 3 months of illness, there is a cessation of the febrile condition with a persistence or worsening of pre-existing symptoms. ${ }^{3}$ The manifestations include arthritis/ arthralgia, oedematous polyarthritis of the fingers and toes, pain, morning stiffness and severe tenosynovitis (especially of the wrists, hands and ankles). ${ }^{4}$ During the subacute phase, the use of common analgesics (paracetamol or dipyrone)/opioids is recommended; however, non-steroidal anti-inflammatory drugs (NSAIDs) and/or adjuvant medications (anticonvulsants or antidepressants) can be used to treat pain in refractory cases. ${ }^{5}$ In patients with moderate musculoskeletal pain, the French Guidelines ${ }^{6}$ recommend using prednisone $10 \mathrm{mg} /$ day for five days and withdrawal over 10 days; for severe cases, a regimen of $0.5 \mathrm{mg} / \mathrm{kg} /$ day for five days and dose reduction within 10 days is used. The Ministry of Health of Brazil and a review conducted by de Brito et al. ${ }^{7}$ recommend using $0.5 \mathrm{mg} /$ $\mathrm{kg} /$ day (maximum dose $40 \mathrm{mg}$ /day) until symptom resolution, followed by gradual withdrawal of $5 \mathrm{mg} /$ week, not to exceed 21 days of treatment. ${ }^{3,7}$ Considering the lack of uniformity in the therapeutic proposals at this stage of the disease, especially regarding the dose and time of corticosteroid use, in addition to the understanding that a higher dose and longer use of corticosteroids lead to greater chances of adverse effects, the present study was carried out to evaluate the effect of corticosteroid therapy on the treatment of patients with CHIKV infection during the subacute phase.

\section{Methods}

A prospective cohort study was carried out involving patients with CHIKV in the subacute phase treated at the Tropical Medicine Center of Pará Federal University (TMC-UFPA), Brazil. The data were collected from January 2019 to January 2020. During this period, 96 patients in the subacute phase were treated; after applying the inclusion and exclusion criteria, a sample of 65 patients was obtained for this research.Patients of both sexes aged 18 years or older with a previous diagnosis of CHIKV infection were included. All patients received a diagnosis of CHIKV based on the positivity of serological tests ${ }^{8,9}$ and confirmation of the diagnostic criteria for Chikungunya virus fever. ${ }^{10}$ Patients who had any cognitive impairment that precluded the interview, patients with previous autoimmune musculoskeletal diseases, patients with incomplete forms and patients who refused to participate were excluded.The data were collected during the following two time periods: the initial consultation of the patients and the return visit. In addition to information, such as sex, age and time of symptom onset, data related to the clinical manifestations were collected, and a physical examination, in which the occurrence of inflammatory signs was checked and the number of painful and swollen joints was assessed, was performed by a rheumatologist.The sample was characterized using a database created with Microsoft ${ }^{\circledR}$ Office Excel $^{\circledR} 2016$ software. To apply descriptive statistics, measures of position, such as the arithmetic mean and standard deviation, were calculated. Analytical statistics were used to evaluate the results of the categorical variables using the G-test and chi-square test of adherence in the univariate analyses and the G-test of independence in the bivariate analyses. In the comparative analyses between the first and second consultations, the chi-square test and G-test were applied. BioEstat $^{\circledR} 5.3$ software was used to perform the descriptive and analytical statistical analyses. For decision-making purposes, the 5\% level of significance was adopted.

\section{Ethical considerations}

This study was conducted in accordance with the principles of the Declaration of Helsinki after receiving approval from the Research Ethics Committee of the TMC-UFPA under registration number 3.001.616 (CAAE 87376518.9.0000.5172) on November 6, 2018.

\section{Results}

In the present study, 65 patients meeting the criteria for CHIKV infection in the subacute stage of the disease were evaluated. Among these patients, the predominance was female (80\%), with a mean age of $53.5 \pm 13.5$ years (median of 53 years) and disease duration of $50.0 \pm 20.8$ days (median of 60 days). The most frequent comorbidities were arterial hypertension (27.5\%), diabetes mellitus $(12.5 \%)$ and dyslipidaemia (7.5\%).Before attending the TMC-UFPA, it was observed that the patients used drugs to control pain and other initial symptoms of the disease. Among those in which it was possible to identify the treatment performed, the following three classes of drugs were a part of the therapeutic arsenal: common analgesics (paracetamol or dipyrone), NSAID and corticosteroids (oral or injectable deposit formulation). Of these patients, 41.54\% used monotherapy, and $23.08 \%$ used combined therapy (Table 1).In this study, three classes of drugs were used to treat the patients in the subacute phase of the disease, and corticosteroids were the most frequently prescribed (75.4\%) (Table 2).The patients were grouped according to the following two outcomes: cure (those who were completely asymptomatic) (n=17/26.2\%) or entry into the chronic phase of the disease (those who maintained signs and/or symptoms for more than 3 months) ( $n=48 / 73.8 \%$ ) $(\mathrm{p}<0.0001)$.To establish the effect of corticosteroid use, among the 50 patients who used this medication, their physical examination findings at the first and second visits to the TMC-UFPA were compared. The average time between consultations was $30.5 \pm 7.5$ days. An improvement in all evaluated parameters was noted (Table 3). NSAIDs and analgesics were used in cycles of 14 days. The standard dose of corticosteroids was $20 \mathrm{mg}$ /day of prednisone, with a reduction of $5 \mathrm{mg} /$ week; however, changes in the prescription resulted from the peculiarities of each case. In some cases of more intense and disabling symptoms, higher doses were chosen. At other times, the patients themselves increased the dose and/or duration of their medication use. Thus, to facilitate the data analysis, we divided the use of corticosteroids according to the cumulative dose: $\leq 350 \mathrm{mg}$ of prednisone (representing the maximum dose of $20 \mathrm{mg}$ with a reduction of $5 \mathrm{mg} /$ week $(\mathrm{n}=13 / 26 \%)$ and $>350 \mathrm{mg}$ of prednisone (representing the highest and/or longest dose) ( $n=37 / 74 \%)$.There was no statistically significant difference in relation to the cumulative dose of this medication between the outcome of the disease and the use of corticosteroids (Table 4). 
Table 1: Distribution of patients infected with Chikungunya virus in the subacute phase according to the medication used before the first consultation at the Tropical Medicine Center of Pará Federal University, Brazil.

\begin{tabular}{|c|c|c|}
\hline Variable & Frequency (n) & Percentage $(\%)$ \\
\hline \multicolumn{3}{|c|}{ Monotherapy } \\
\hline Corticosteroids (oral) & 8 & 12 \\
\hline NSAID & 6 & 9 \\
\hline Common pain reliever & 12 & 18 \\
\hline Corticosteroids (deposit) & 1 & 2 \\
\hline \multicolumn{3}{|c|}{ Combination therapy } \\
\hline NSAID + Common pain reliever & 5 & 8 \\
\hline Corticosteroids (deposit) + NSAID & 2 & 3 \\
\hline Corticosteroids (deposit) + Corticoid (oral) & 4 & 6 \\
\hline $\begin{array}{l}\text { Corticosteroids (deposit) + NSAID + Common } \\
\text { pain reliever }\end{array}$ & 1 & 2 \\
\hline Corticosteroids (oral) + Common pain reliever & 3 & 5 \\
\hline Not specified & 23 & 35 \\
\hline Total & 65 & 100 \\
\hline
\end{tabular}

NSAIDs non-steroidal anti-inflammatory drugs.

Table 2: Medication prescribed for patients infected with Chikungunya virus in the subacute phase at the first consultation at the Tropical Medicine Center of Pará Federal University, Brazil.

\begin{tabular}{|c|c|c|c|}
\hline Variable & Frequency (n) & Percentage (\%) & p-value \\
\hline Corticosteroids & 50 & 77 & $<0.0001^{\text {a }}$ \\
\hline NSAIDs & 10 & 15 & \\
\hline Common pain reliever & 5 & 8 & \\
\hline
\end{tabular}

${ }^{a}$ chi-square test. NSAIDs non-steroidal anti-inflammatory drugs.

Table 3: Comparison between physical examinations at the first and second consultations of patients infected with Chikungunya virus in the subacute phase at the Tropical Medicine Center of Pará Federal University, Brazil.

\begin{tabular}{|c|c|c|c|c|c|}
\hline \multirow{4}{*}{ Variable } & \multicolumn{4}{|c|}{ Physical exam } & \multirow{4}{*}{ p-value } \\
\hline & \multicolumn{2}{|c|}{ First consultation } & \multicolumn{2}{|c|}{ Second consultation } & \\
\hline & Frequency & Percentage & Frequency & Percentage & \\
\hline & (n) & $(\%)$ & (n) & (\%) & \\
\hline \multicolumn{6}{|c|}{ Number of affected joints } \\
\hline$\geq 5$ & 44 & 88 & 20 & 40 & $<0.0001^{\mathrm{a}}$ \\
\hline 1 to 4 & 6 & 12 & 21 & 42 & \\
\hline None & 0 & 0 & 9 & 18 & \\
\hline \multicolumn{6}{|c|}{ Arthritis } \\
\hline Absent & 24 & 48 & 36 & 72 & $0.0247^{\mathrm{b}}$ \\
\hline Present & 26 & 52 & 14 & 28 & \\
\hline \multicolumn{6}{|c|}{ Morning stiffness } \\
\hline Absent & 40 & 80 & 43 & 86 & $0.5944^{\mathrm{b}}$ \\
\hline Present & 10 & 20 & 7 & 14 & \\
\hline \multicolumn{6}{|c|}{ Diffuse oedema of hands and feet } \\
\hline Absent & 20 & 40 & 41 & 82 & $<0.0001^{\mathrm{b}}$ \\
\hline Present & 30 & 40 & 9 & 18 & \\
\hline
\end{tabular}

${ }^{\mathrm{a} G}$-test for adherence, ${ }^{\mathrm{b}} \mathrm{chi}$-square test. 
Table 4: Relation between the outcome and cumulative dose of corticosteroids used in the treatment of patients infected with Chikungunya virus in the subacute phase seen at the Tropical Medicine Center of Pará Federal University, Brazil.

\begin{tabular}{|c|c|c|c|c|}
\hline \multirow{2}{*}{ Variable } & \multicolumn{4}{|c|}{ Outcome } \\
\cline { 2 - 6 } & \multicolumn{2}{|c|}{ Cured } & \multicolumn{3}{c|}{ Chronic phase } \\
\cline { 2 - 6 } & Frequency (n) & Percentage(\%) & Frequency (n) & Percentage (\%) \\
\hline$\leq 350 \mathrm{mg}$ & 3 & 23,1 & 10 & 76,9 \\
\hline$>350 \mathrm{mg}$ & 8 & 21.6 & 29 & 78.4 \\
\hline
\end{tabular}

\section{Discussion}

This study revealed that the use of high doses of corticosteroids (cumulative dose $>350 \mathrm{mg}$ of prednisone) does not improve outcomes related to healing or chronification in individuals with subacute CHIKV infection. This finding is important, as it can prevent patients from being subjected to excessive and/or prolonged doses of corticosteroids, which could increase the occurrence of adverse effects of the medication.The recommended drugs for the treatment of the subacute phase of Chikungunya Fever are analgesics, NSAIDs and corticosteroids., ${ }^{3,5,6}$ The use of corticosteroids in this condition is a common practice depending on the physician's experience in using this medication. The ability to provide a more objective recommendation, especially for primary care physicians, can facilitate the adoption of safer practices. For example, according to a study by Simon et al. ${ }^{6}$ in 6 severe cases of musculoskeletal pain, the acceptable dose of prednisone can reach $0.5 \mathrm{mg} / \mathrm{kg} /$ day for 5 days, followed by a dose reduction over 10 days, not to exceed 4 weeks. In a $70 \mathrm{~kg}$ patient, this cumulative dose could be approximately $525 \mathrm{mg}$ (35mg/5 days; $20 \mathrm{mg} / 10$ days; $15 \mathrm{mg} / 5$ days; $10 \mathrm{mg} / 5$ days; and $5 \mathrm{mg} / 5$ days). Even in a $60 \mathrm{~kg}$ individual, the cumulative dose $(500 \mathrm{mg}$ ) could exceed the recommended dose in this research $(\leq 350 \mathrm{mg})$.In another example, following the recommendations of the Ministry of Health of Brazil ${ }^{3}$ and de Brito et al. ${ }^{7}$ the dose of prednisone should be $0.5 \mathrm{mg} / \mathrm{kg} /$ day (maximum dose $40 \mathrm{mg} /$ day) until the resolution of symptoms, followed by gradual withdrawal of $5 \mathrm{mg} /$ week, not to exceed 21 days of treatment. For example, a $70 \mathrm{~kg}$ individual could receive $630 \mathrm{mg}$ (35mg/7 days; $30 \mathrm{mg} / 7$ days; and $25 \mathrm{mg} / 7$ days). Notably, in practice, a dose of $25 \mathrm{mg}$ /day of prednisone could not be stopped abruptly after 21 days due to the risk of triggering adrenal insufficiency. The reduction should be gradual, which could further increase the cumulative dose to be used by the patient.

Thus, the dose usually used in the TMC-UFPA outpatient clinic, i.e., $20 \mathrm{mg}$ of prednisone $/ 7$ days and a reduction of $5 \mathrm{mg} /$ week, results in a cumulative dose of $350 \mathrm{mg}$, representing practical and objective guidance, and has shown results similar to those with higher doses.In the present study, it was not possible to carry out a detailed analysis of the use of deposit corticosteroid, as these drugs were prescribed for only 8 patients; however, in cases of more obvious symptomatology, in Brazil, the prescription of corticosteroid injection is common. A medication widely used for this purpose in Brazil includes $7 \mathrm{mg}$ of betamethasone, which is equivalent to $70 \mathrm{mg}$ of prednisone. In these situations, the prednisone dose that follows the use of the deposit corticosteroid could have the following scheme: $20 \mathrm{mg} / 5$ days; $15 \mathrm{mg} / 5$ days; $10 \mathrm{mg} / 5$ days; and $5 \mathrm{mg} / 5$ days. The total cumulative dose obtained by adding the injectable and oral regimen could be $320 \mathrm{mg}$. In practice, an initial dose of injectable corticosteroids actually results in the rapid relief of symptoms in the most serious situations.Based on the results of the Chikbrasil Cohort, the Brazilian Society of Rheumatology suggests the use of lower doses (5 to $20 \mathrm{mg}$ /day) of prednisone or prednisolone, with slow and progressive reduction according to the resolution of joint symptoms, as a study demonstrated that the use of corticosteroids in the subacute phase led to a more significant clinical improvement with doses above $10 \mathrm{mg} /$ day. However, no additional benefit was obtained from using more than $20 \mathrm{mg} /$ day of prednisone. $^{5}$

In the present study, the patients were re-evaluated after the institution of treatment with corticosteroids. A noticeable reduction in the number of affected joints was observed, resulting in $40 \%$ with 5 or more affected joints, which is much lower than the initial $88 \%$. Similarly, in the second assessment, $72 \%$ had no signs of arthritis, $86 \%$ had no morning stiffness, and $82 \%$ no longer had diffuse oedema of the hands and feet.The disease outcome following the treatment employed demonstrated a predominance of chronic evolution (73.85\%). These rates are considered high, suggesting that the treatment performed is capable of clinically improving the patients' condition but not avoiding chronic outcomes in most cases. The data in the literature indicate a chronicity rate of $25 \%$ to $75 \%$, while widely varying among studies. ${ }^{3,11-13}$ This variability may be due to methodological or geographical differences and the presence of comorbidities. It is relevant to highlight a limitation of this study. We were unable to quantify the dose of corticosteroids used prior to the admission of the patients to TMC-UFPA. We chose not to include these data to avoid errors in patient recall, as some reported doses differ from those used, which could influence the analysis.

\section{Conclusion}

It is concluded that for patients infected with CHIKV in the subacute phase, doses of prednisone above $350 \mathrm{mg}$ do not affect the outcome, and the preference for the use of corticosteroids at the lowest dose for the shortest possible time should be reinforced.

\section{Acknowledgments}

None.

\section{Funding}

The authors have not declared a specific grant for this research from any funding agency in the public, commercial or not-for-profit sectors. 


\section{Conflicts of Interest}

The authors declare that there is no conflict of interest.

\section{Consent to participate}

A written informed consent was obtained from all the participants included in this study and no identifying information of any participant was included in this paper.

\section{Author's Contribution}

JAP, VWV, MSMQ RCMS, CAMC were responsible for data collection and analysis. JAP, VWV, CAMC contributed to the writing of the manuscript. CAMC revised the manuscript.

\section{References}

1. Cleton N, Koopmans M, Reimerink J, et al. Come fly with me: review of clinically important arboviruses for global travelers. J Clin Virol. 2012;55(3):191-203.

2. Ministério da Saúde (BR). Secretaria de Vigilância em Saúde. Boletim Epidemiológico. Monitoramento dos casos de dengue até a Semana Epidemiológica (SE) 36 e febre de chikungunya até a SE 37 de 2014. Vol 45. $N^{\circ}$ 21. Setembro de 2014. Brasília: Ministério da Saúde, 2014.

3. Ministério da Saúde (BR). Secretaria de Vigilância em Saúde. Chikungunya: manejo clínico. Brasília: Ministério da Saúde, 2017.

4. Parola P, Simon F, Oliver M. Tenosynovitis and vascular disorders associated with Chikungunya virus-related rheumatism. Clin Infect Dis. 2007;45(6):801-802.
5. Marques CDL, Duarte ALBP, Ranzolin A et al. Recomendações da Sociedade Brasileira de Reumatologia para diagnóstico e tratamento da febre chikungunya. Parte 1 - Diagnóstico e situações especiais. Rev Bras Reumatol. 2017;57(supl.2):s421-s437.

6. Simon F, Parola P, Grandadam M, et al. Chikungunya infection: an emerging rheumatism among travelers returned from Indian Ocean islands. Report of 47 cases. Medicine (Baltimore.) 2007;86(3):123-137.

7. De Brito CAA, von Sohsten AKR, Clezio Leitão CCS, et al. Pharmacologic management of pain in patients with Chikungunya: a guideline. Rev Soc Bras Med Trop. 2016;49(6):668-679.

8. Galo SS, González K, Téllez Y, et al. Development of in-house serological methods for diagnosis and surveillance of chikungunya. Rev Panam Salud Publica. 2017;41:e56.

9. Johnson BW, Russell BJ, Goodman CH. Laboratory diagnosis of Chikungunya Virus infections and commercial sources for diagnostic assays. J Infect Di. 2016;241(Suppl 5):S471-S474.

10. Wahid B, Ali A, Rafique S, et al. Global expansion of chikungunya virus: mapping the 64-year history. Int J Infect Dis. 2017;58:69-76.

11. Couzigou B, Criquet-Hayot A, Javelle E, et al. Occurrence of Chronic Stage Chikungunya in the General Population of Martinique during the First 2014 Epidemic: A Prospective Epidemiological Study. Am J Trop Med Hyg. 2018;99(1):182-190.

12. Schilte C, Staikovsky F, Couderc T, et al. Chikungunya virus-associated long-term arthralgia: a 36-month prospective longitudinal study. PLoS Negl Trop Dis. 2013;7(3):e2137.

13. Sissoko D, Malvy D, Ezzedine K et al. Post-epidemic Chikungunya disease on Reunion Island: course of rheumatic manifestations and associated factors over a 15-month period. PLoS Negl Trop Dis. 2009;3(3):e389. 